\title{
Resuscitation from out-of-hospital cardiac arrest: is survival dependent on who is available at the scene?
}

\author{
L H Soo, D Gray, T Young, N Huff, A Skene, J R Hampton
}

\begin{abstract}
Objective-To determine whether survival from out-of-hospital cardiac arrest is influenced by the on-scene availability of different grades of ambulance personnel and other health professionals.

Design-Population based, retrospective, observational study.
\end{abstract}

Setting-County of Nottinghamshire with a population of one million.

Subjects-All 2094 patients who had resuscitation attempted by Nottinghamshire Ambulance Service crew from 1991 to 1994; study of 1547 patients whose arrest were of cardiac aetiology.

Main outcome measures-Survival to hospital admission and survival to hospital discharge.

Results-Overall survival from out-ofhospital cardiac arrest remains poor: 221 patients $(14.3 \%)$ survived to reach hospital alive and only $94(6.1 \%)$ survived to be discharged from hospital. Multivariate logistic regression analysis showed that the chances of those resuscitated by technician crew reaching hospital alive were poor but were greater when paramedic crew were either called to assist technicians or dealt with the arrest themselves (odds ratio 6.9 (95\% confidence interval 3.92 to 26.61)). Compared to technician crew, survival to hospital discharge was only significantly improved with paramedic crew (3.55 (1.62 to 7.79)) and further improved when paramedics were assisted by either a health professional (9.91 (3.12 to 26.61)) or a medical practitioner (20.88 (6.72 to 64.94)).

Conclusions-Survival from out-ofhospital cardiac arrest remains poor despite attendance at the scene of the arrest by ambulance crew and other health professionals. Patients resuscitated by a paramedic from out-of-hospital cardiac arrest caused by cardiac disease were more likely to survive to hospital discharge than when resuscitation was provided by an ambulance technician. Resuscitation by a paramedic assisted by a medical practitioner offers a patient the best chances of surviving the event. (Heart 1999;81:47-52)

Keywords: out-of-hospital; cardiac arrest; paramedic; technician

Geography, University of Nottingham

N Huff

Correspondence to: Dr Soo.

Accepted for publication 8 September 1998
Out-of-hospital cardiac arrest has a high mortality, but resuscitation, particularly defibrillation, may increase the chances of a patient surviving the event and being discharged from hospital. ${ }^{1}$ Different approaches have been proposed to provide prompt resuscitation in the community. ${ }^{2}$

Over the past 10 years the United Kingdom emergency ambulance service has replaced the deployment of medical technicians trained only in basic life support and equipped with a defibrillator with paramedics trained in providing advanced cardiac life support (ACLS) including endotracheal intubation, emergency drug use, and manual defibrillation. The effectiveness of this policy in improving survival of outof-hospital cardiac arrest has been questioned, ${ }^{3}$ but prospective studies are impossible because all front line emergency ambulance in the United Kingdom now have at least one crew member who is paramedic trained.

Medical practitioners and health professionals such as nurses, St John Ambulance personnel, police, and firemen are commonly trained in resuscitation and already provide basic life support pending the arrival of the emergency ambulance service. However, following cardiac arrest in the community, most medical practitioners and health professionals are dependent on the emergency ambulance service to provide defibrillators and advanced cardiac life support. The outcome of out-of-hospital cardiac arrest is improved when medical practitioners and health care trained professionals witness the event. ${ }^{4}$ We wanted to ascertain whether survival was improved when medical practitioners and health care trained professionals assisted ambulance paramedics and technicians, who now provide the majority of resuscitation in the community.

Using data from the Nottingham heart attack register, ${ }^{5}$ which has monitored coronary events in the Nottingham community since 1973, we carried out a comprehensive review of all cardiopulmonary resuscitations (CPR) by the Nottinghamshire Ambulance Service between 1 January 1991 and 31 December 1994. We were able to assess whether survival was related to the type of ambulance crew attending the victim and whether it was influenced by the on-scene availability of medical practitioners and health professionals.

Methods

As a routine, details of all out-of-hospital cardiac arrest attempts by the Nottinghamshire Ambulance Service were collected by the Nottingham heart attack register. ${ }^{5}$ The ambulance patient report form records the circumstances of the "999" call, the ambulance crew members, their response times, and all interventions, whether by bystanders or crew. 
Where the patient report form could not be located, the records section of the following were searched: the four Nottinghamshire accident and emergency departments based at Queen's Medical Centre Nottingham, King's Mill Hospital Mansfield, and the general hospitals at Newark and Bassetlaw; the various coronary care units and intensive care units; and the records of each ambulance station dispatch and control unit. The records of the ambulance dispatch and control unit were comprehensively reviewed and provided a cross reference for the completeness of the collection of patient report forms and timing of events.

Where appropriate, further information was obtained from the accident and emergency record sheets and, for those who were admitted to hospital, the inpatient case records. The coroner's records and inpatient case records were also examined to identify all those sustaining a cardiac arrest from a cardiac cause (ICD 390 to 414 and 420 to 429 ), usually as a result of a necropsy examination. These patients form the basis of this study.

The presenting rhythm for each episode of cardiac arrest was obtained from the print out of the defibrillator unit. All resuscitation attempts where the presenting rhythm was not recorded were also reviewed.

The patient record form documented the names of all ambulance crew responding to each emergency call and from this the type of training could be identified. When the resuscitation efforts of the ambulance crew were assisted by some other person, this was recorded.

Patients may have been attended by ambulance crew comprising "technicians only" (consisting of two technicians), "paramedic

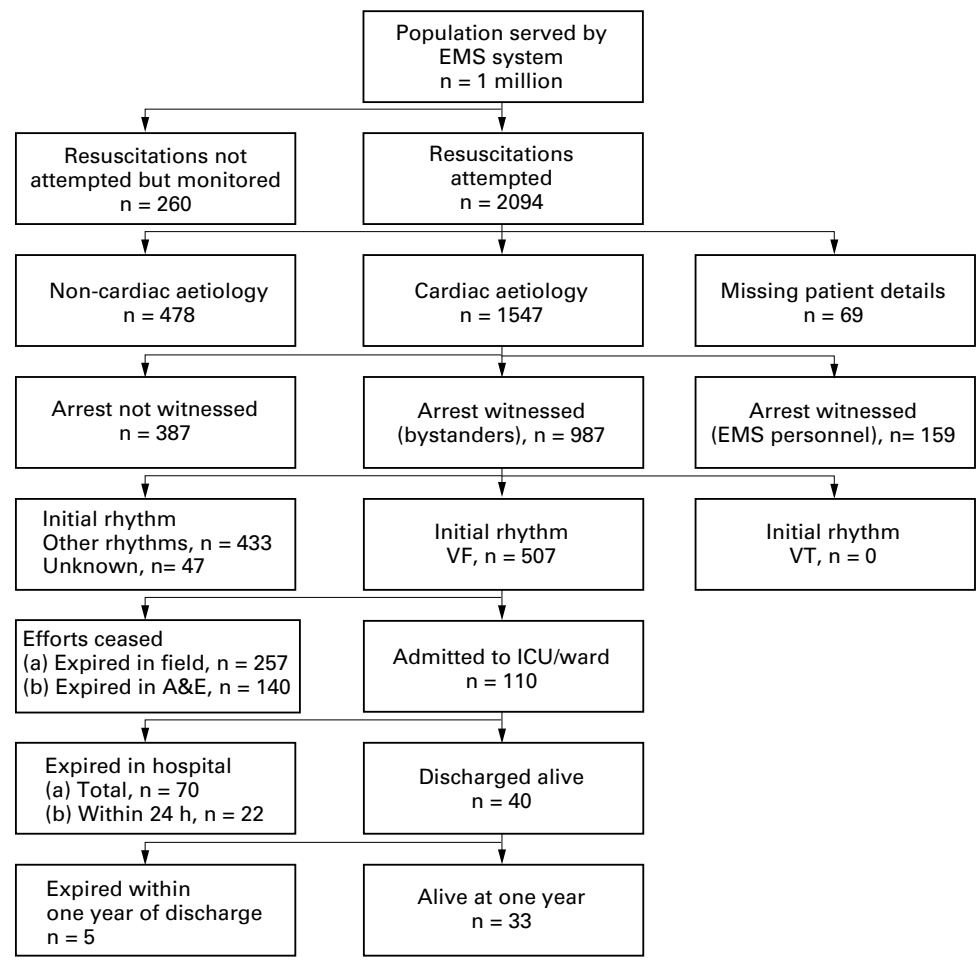

Figure 1 Utstein style template of the Nottinghamshire ambulance resuscitation attempts and outcome for 1991 to 1994. only" crew (where at least one member was a paramedic), or technicians and "backup" paramedic (where the technician crew had requested assistance from a paramedic team). Assistance may have been provided by either a medical practitioner or another health professional trained in basic life support such as nurse, police, fireman, or St John Ambulance personnel, or personnel from another ambulance (infrequently, a second crew of either technicians or paramedics could be called to assist a crew of a similar grade). Medical practitioners were usually general practitioners but also included doctors attending major public events or "good Samaritans."

The length of experience of the more experienced "leading" crew member of the first responding team was taken as the interval between the date of completing either paramedic training or technician training and each resuscitation attempt. The leading crew member was the more experienced technician in the technician crew, or the more experienced paramedic in the paramedic crew.

All data were collected in the Utstein style format. ${ }^{6}$ In accordance with the Utstein recommendation, the following causes of cardiac arrest were excluded: sudden infant deaths, drug overdose, suicide, drowning, hypoxia, exsanguination, cerebrovascular accident, subarachnoid haemorrhage, trauma, ruptured aortic aneurysm, and pulmonary thromboembolism.

Socioeconomic status was measured by the Townsend index of deprivation ${ }^{7}$ using the post code of the patient, with higher positive value suggesting greater deprivation. This index was derived using data from the 1991 census, combining four variables selected as representative of material wellbeing: unemployment, car ownership, non-owner occupation, and household overcrowding.

\section{STATISTICAL EVALUATION}

Univariate data analysis was performed using the $\chi^{2}$ test and the Kruskal-Wallis test. A logistic regression model was fitted to determine whether the type of ambulance crew, together with any assistance provided by either a medical practitioner or a health professional, affected survival. All tests of significance were two tailed, with a probability (p) value less than 0.05 considered significant. The S-Plus statistical package (version 3.3$)^{8}$ was used for all analyses.

\section{Results}

RESUSCITATION IN THE COMMUNITY

During the four year study period, Nottinghamshire ambulance crews carried out 2094 resuscitations following collapse in the community. The management and outcome of the cardiac arrests is shown in fig 1 in the Utstein style. ${ }^{6}$ The patient report form could not be located for 69 patients; of these, only seven were admitted to a hospital ward, all of whom died while in hospital, so these were excluded from further analysis. A total of 1547 cardiac arrests had an underlying cardiac cause as determined from 1113 necropsy reports (71.9\%), 364 death certificates $(23.5 \%)$, and 70 hospital case notes 
Table 1 Distribution of out-of-hospital cardiac arrests for each year attended by the type of crew with any assistance from either a medical practitioner (MP) or a health professional (HP)

\begin{tabular}{lcclcccrr}
\hline Year & $\begin{array}{l}\text { Technicians } \\
\text { only (\%) }\end{array}$ & $\begin{array}{l}\text { Paramedic } \\
\text { only (\%) }\end{array}$ & $\begin{array}{l}\text { Technicians } \\
\text { and backup } \\
\text { paramedic (\%) }\end{array}$ & $\begin{array}{l}\text { Technicians } \\
\text { and MP (\%) }\end{array}$ & $\begin{array}{l}\text { Technicians } \\
\text { and HP (\%) }\end{array}$ & $\begin{array}{l}\text { Paramedic } \\
\text { and MP (\%) }\end{array}$ & $\begin{array}{l}\text { Paramedic } \\
\text { and HP (\%) }\end{array}$ & $p$ Value \\
\hline 1991 & $218(41.9)$ & $37(6.7)$ & $18(12.3)$ & $23(41.1)$ & $41(42.3)$ & $2(2.9)$ & $6(5.6)$ & $<0.001$ \\
1992 & $154(27.9)$ & $119(21.6)$ & $39(26.7)$ & $15(26.8)$ & $26(26.8)$ & $21(30.0)$ & $21(19.6)$ & 0.062 \\
1993 & $103(19.8)$ & $200(36.3)$ & $53(36.3)$ & $8(14.3)$ & $18(18.6)$ & $25(35.7)$ & $38(35.5)$ & $<0.001$ \\
1994 & $45(8.7)$ & $195(35.4)$ & $36(24.7)$ & $10(17.9)$ & $12(12.4)$ & $22(31.4)$ & $42(39.3)$ & $<0.001$ \\
\hline
\end{tabular}

(4.5\%). The study excluded 4133 cases in which resuscitation was not attempted by the ambulance crew, either because the patient had rigor mortis or because there had been no bystander resuscitation for at least 15 minutes before the ambulance crew arrived. Among these cases, there were 260 patients who had their heart rhythm monitored, probably because of doubt about the timing of arrest. Of these 260 cases, $158(60.8 \%)$ had underlying cardiac cause for their death, determined from 126 necropsy reports $(79.7 \%)$ and 32 death certificates (20.3\%).

AMBULANCE PERSONNEL

The number of ambulance personnel increased during the study and the proportion of qualified paramedics, as opposed to trained emergency medical technicians, in the Nottinghamshire Ambulance Service increased from 22 (11.0\%) in 1991 to $116(39.7 \%)$ by 1994 . As a result of this, the proportion of out-of-hospital cardiac arrests attended by "paramedic" crew increased between 1991 and 1994 (table 1). Within each group, there were experienced and relatively inexperienced crew members.

PREDETERMINED TIME INTERVALS FOR EVENTS ASSOCIATED WITH OUT-OF-HOSPITAL CARDIAC ARREST

The time intervals between the ambulance crew receiving the call to the time of arrival (the call-response interval) and to the time of defibrillation (call to first defibrillator shock inter$v a l$ ), the time interval between arrival at and departure from the scene of arrest (at-scene interval), and the time interval from leaving the scene of arrest to arrival in hospital (travel to hospital interval) are shown in table 2 .

There was no difference in call to first defibrillator shock interval or in the call to response interval. Paramedics generally spent longer on scene than technicians, even when assisted by either a medical practitioner or other health professional. The at-scene interval was also prolonged when technicians requested help from "backup" paramedics. The travel to hospital interval was found to be prolonged when paramedics were assisted by a medical practitioner, probably because most of the patients would have received all the necessary treatment at scene and were unlikely to seek further immediate help from the accident and emergency department.

\section{PATIENT DEMOGRAPHICS}

The characteristics of the 1547 patients in the study and details of the ambulance crew who attended the cardiac arrest and any assistance they received at the scene of the arrest are shown in table 3.

The presenting rhythm was recorded in 1468 cases $(94.9 \%)$. An initial rhythm could not be identified in 79 cases -75 of which were

Table 2 Median time intervals (interquartile range) in minutes for each stage of response for each type of ambulance crew with assistance from the various health professionals

\begin{tabular}{|c|c|c|c|c|c|c|c|c|}
\hline Intervals & $\begin{array}{l}\text { Technicians } \\
\text { only }\end{array}$ & $\begin{array}{l}\text { Paramedic } \\
\text { only }\end{array}$ & $\begin{array}{l}\text { Technicians and } \\
\text { backup paramedic }\end{array}$ & $\begin{array}{l}\text { Technicians } \\
\text { and } M P\end{array}$ & $\begin{array}{l}\text { Technicians } \\
\text { and } H P\end{array}$ & $\begin{array}{l}\text { Paramedics } \\
\text { and } M P\end{array}$ & $\begin{array}{l}\text { Paramedics } \\
\text { and } H P\end{array}$ & $p$ Value \\
\hline Call to first defibrillator shock & $10(8,14)$ & $10(7,15)$ & $10(7,13)$ & $9(8,13)$ & $10(8,14)$ & $11(8,16)$ & $9(6,12)$ & 0.491 \\
\hline Call to response & $6(4,9)$ & $6(4,9)$ & $6(4,8)$ & $7(4,9)$ & $6(4,8)$ & $7(4,10)$ & $6(4,8)$ & 0.123 \\
\hline At scene of arrest & $16(11,24)$ & $31(23,40)$ & $40(31,48)$ & $26(16,37)$ & $28(17,41)$ & $34(24,49)$ & $33(27,42)$ & $<0.001$ \\
\hline Departure from scene to arrival in A\&E & $8(5,12)$ & $8(5,12)$ & $7(5,12)$ & $8(5,12)$ & $9(6,12)$ & $10(5,16)$ & $6(4,8)$ & $<0.001$ \\
\hline
\end{tabular}

HP, health professional; MP, medical practitioner.

Table 3 Characteristics of patients and details of out-of-hospital cardiac arrests treated by paramedics or technicians with help from various health professionals

\begin{tabular}{|c|c|c|c|c|c|c|c|c|}
\hline & Technicians only & Paramedic only & $\begin{array}{l}\text { Technicians } \\
\text { and backup } \\
\text { paramedic }\end{array}$ & $\begin{array}{l}\text { Technicians } \\
\text { and } M P\end{array}$ & $\begin{array}{l}\text { Technicians } \\
\text { and HP }\end{array}$ & $\begin{array}{l}\text { Paramedics } \\
\text { and } M P\end{array}$ & $\begin{array}{l}\text { Paramedics } \\
\text { and } H P\end{array}$ & $p$ Value \\
\hline Number & 520 & 551 & 146 & 56 & 97 & 70 & 107 & - \\
\hline Median age (IQR) & $69(61,76)$ & $68(59,75)$ & $67(55,73)$ & $67(58,71)$ & $65(57,72)$ & $71(61,79)$ & $65(57,73)$ & 0.001 \\
\hline Male & $400(76.9)$ & $398(72.2)$ & $110(75.3)$ & $39(69.6)$ & $79(81.4)$ & $51(72.9)$ & $89(83.2)$ & 0.114 \\
\hline \multicolumn{9}{|l|}{ Median Townsend index } \\
\hline$(\mathrm{IQR})$ & $1.5(-1.0,3.7)$ & $0.8(-1.8,3.7)$ & $2.8(-0.8,4.2)$ & $0.0(-2.7,2.5)$ & $1.7(-0.6,3.8)$ & $0.7(-2.0,2.6)$ & $1.2(-0.4,3.5)$ & 0.001 \\
\hline Previous myocardial infarct & $241(46.3)$ & $233(42.3)$ & $66(45.2)$ & $23(41.1)$ & $46(47.4)$ & $20(28.6)$ & $50(46.7)$ & 0.141 \\
\hline Presenting rhythm VF & $192(36.9)$ & $266(48.3)$ & $90(61.6)$ & $31(55.4)$ & $50(51.5)$ & $38(54.3)$ & $61(57.0)$ & $<0.001$ \\
\hline Presenting rhythm other & $264(50.8)$ & $281(51.0)$ & $56(38.4)$ & $21(37.5)$ & $40(41.2)$ & $32(45.7)$ & $46(43.0)$ & 0.025 \\
\hline Presenting rhythm unknown & $64(12.3)$ & $4(0.7)$ & $0(0.0)$ & $4(7.1)$ & $7(7.2)$ & $0(0.0)$ & $0(0.0)$ & NA \\
\hline Witnessed arrest & $307(59.0)$ & $341(61.9)$ & $99(67.8)$ & $42(75.0)$ & $65(67.0)$ & $53(75.7)$ & $80(74.8)$ & 0.002 \\
\hline Bystander CPR & $123(23.7)$ & $154(27.9)$ & $41(28.1)$ & $40(71.4)$ & $57(58.8)$ & $47(67.1)$ & $54(50.5)$ & $<0.001$ \\
\hline \multicolumn{9}{|l|}{ Witnessed arrest by ambulance } \\
\hline crew & $60(11.5)$ & $56(10.2)$ & $17(11.6)$ & $5(8.9)$ & $9(9.3)$ & $6(8.6)$ & $6(5.6)$ & 0.654 \\
\hline Cardiac arrest at home & $362(69.6)$ & $398(72.2)$ & $111(76.0)$ & $36(64.3)$ & $57(58.8)$ & $56(80.0)$ & $61(57.0)$ & 0.001 \\
\hline
\end{tabular}

Values are $\mathrm{n}(\%)$ unless otherwise stated.

$\mathrm{CPR}$, cardiopulmonary resuscitation; HP, health professional; IQR, inter quartile range; MP, medical practitioner; VF, ventricular fibrillation. 
Table 4 Outcome of patients with ventricular fibrillation as presenting rhythm

\begin{tabular}{|c|c|c|c|c|c|c|c|c|}
\hline & $\begin{array}{l}\text { Technicians only } \\
(n=192)\end{array}$ & $\begin{array}{l}\text { Paramedic only } \\
(n=266)\end{array}$ & $\begin{array}{l}\text { Technicians and } \\
\text { backup paramedic } \\
(n=90)\end{array}$ & $\begin{array}{l}\text { Technicians and } \\
M P(n=37)\end{array}$ & $\begin{array}{l}\text { Technicians and } \\
H P(n=50)\end{array}$ & $\begin{array}{l}\text { Paramedics and } \\
M P(n=38)\end{array}$ & $\begin{array}{l}\text { Paramedics and } \\
H P(n=61)\end{array}$ & $p$ Value \\
\hline BID/home & $116(60.4)$ & $113(42.5)$ & $30(33.3)$ & $14(37.8)$ & $20(40.0)$ & $21(55.3)$ & $22(36.1)$ & $<0.001$ \\
\hline DID (A\&E) & $46(24.0)$ & $85(32.0)$ & $35(38.9)$ & $6(16.2)$ & $11(22.0)$ & $2(5.3)$ & $22(36.1)$ & 0.001 \\
\hline Admitted alive & $30(15.6)$ & $68(25.6)$ & $25(27.8)$ & $11(29.7)$ & $19(38.0)$ & $15(39.5)$ & $17(27.9)$ & 0.005 \\
\hline Discharged alive & $21(10.9)$ & $28(10.5)$ & $7(7.8)$ & $5(13.5)$ & $7(14.0)$ & $9(23.7)$ & $8(13.1)$ & 0.266 \\
\hline
\end{tabular}

Values are $\mathrm{n}(\%)$.

BID, brought in dead; DID, died in accident and emergency department (A\&E); MP, medical practitioner; HP, health professional.

attended by ambulance technicians-for two reasons. First, not every emergency ambulance was equipped with a defibrillator in the first few months of the study; and second, while conducting basic life support, a "scoop and run" policy was sometimes preferred when the patient collapsed close to the accident and emergency department.

There were no significant differences in patients' sex and in the proportion with previous myocardial infarction. However, age and Townsend index of the patient, witnessed arrest, bystander resuscitation, and presenting rhythm of ventricular fibrillation or other rhythm (asystole, fine ventricular fibrillation, electromechanical dissociation, pulseless idioventricular rhythm) were found to be significantly different across the groups. There were fewer patients with a presenting rhythm of ventricular fibrillation attended by "technicians only" crew.

Patients attended by ambulance crews with assistance from either a medical practitioner or a health professional were significantly more likely to have had CPR before the arrival of the ambulance. In the groups that had assistance by a medical practitioner or a health professional, there was a high proportion of witnessed arrests and bystander resuscitations because the medical practitioner or health professional would have been the bystander who witnessed the arrest, and only infrequently would they arrive at the scene when resuscitation by either the ambulance staff or a lay person was in progress and lend a helping hand. Health professionals were less likely to assist resuscitation of cardiac arrests that occurred in the home of the patient.

SURVIVAL FROM OUT-OF-HOSPITAL CARDIAC ARREST

Overall, 221 patients (14.3\%) survived to be admitted to hospital, but of these only 94 ( $6.1 \%$ of the original group) survived to be discharged from hospital. When the presenting rhythm was ventricular fibrillation, survival chances were significantly improved, as 85 of $728(11.7 \%)$ were discharged from hospital (table 4). These represent $90.4 \%$ of the total of 94 survivors in the study.

A presenting rhythm other than ventricular fibrillation was associated with extremely poor survival prospects, as only 67 of 740 patients $(0.8 \%)$ survived to leave hospital.

LOGISTIC REGRESSION ANALYSIS

The odds ratios of surviving to admission and to discharge from hospital are shown in table 5. Univariate analysis showed that the distributions for age, Townsend index, number of arrests per year (adjusted for the changing proportion of paramedic and technician crews), length of experience of leading crew member, presenting rhythm, travel to hospital interval, at-scene interval, location of arrest, witnessed arrest by bystander, and bystander CPR were found to be different across the groups, and the logistic regression model was adjusted to take these factors into account.

\section{Survival to hospital}

The chances of reaching hospital alive were lowest when a technicians only crew responded to an emergency call, while management by a paramedic only crew gave significantly better survival chances $(6.9 \%$ v $15.6 \%$, respectively, table 5). Chances improved for the technicians when they had any form of assistance, but patients who had the greatest chances of survival were those who were attended by paramedics assisted by either a health professional $(20.6 \%)$ or a medical practitioner $(24.3 \%)$.

\section{Survival to hospital discharge}

Survival chances were generally poor (table 5). Patients with the lowest chance of surviving to hospital discharge were those who were attended by a technician only crew $(4.4 \%)$. A

Table 5 Out-of-hospital cardiac arrest survival to admission and to discharge with crude and adjusted odds ratios

\begin{tabular}{|c|c|c|c|c|c|c|c|}
\hline & $\begin{array}{l}\text { Technicians } \\
\text { crew }\end{array}$ & Paramedic crew & $\begin{array}{l}\text { Technicians and } \\
\text { backup paramedic }\end{array}$ & $\begin{array}{l}\text { Technicians and } \\
M P\end{array}$ & $\begin{array}{l}\text { Technicians and } \\
H P\end{array}$ & $\begin{array}{l}\text { Paramedics and } \\
M P\end{array}$ & $\begin{array}{l}\text { Paramedics and } \\
H P\end{array}$ \\
\hline Number of survivors to admission (\%) & $36(6.9)$ & $86(15.6)$ & $29(19.9)$ & $11(19.6)$ & $20(20.6)$ & $17(24.3)$ & $22(20.6)$ \\
\hline Crude odds ratio $(95 \% \mathrm{CI})$ & $1.00(-)$ & $\begin{array}{l}2.49^{\star \star \star} \\
(1.65 \text { to } 3.74)\end{array}$ & $\begin{array}{l}3.33^{\star \star \star} \\
(1.97 \text { to } 5.65)\end{array}$ & $\begin{array}{l}3.29^{\star \star} \\
(1.57 \text { to } 6.89)\end{array}$ & $\begin{array}{l}3.49^{\star \star \star} \\
(1.92 \text { to } 6.34)\end{array}$ & $\begin{array}{l}4.31^{\star \star \star} \\
(2.27 \text { to } 8.19)\end{array}$ & $\begin{array}{l}3.48^{\star \star \star} \\
(1.95 \text { to } 6.20)\end{array}$ \\
\hline Adjusted odds ratio $(95 \% \mathrm{CI})$ & $1.00(-)$ & $\begin{array}{l}6.94^{\star \star \star} \\
(3.92 \text { to } 12.29)\end{array}$ & $\begin{array}{l}7.16^{\star \star \star} \\
\text { (3.61 to } 14.22 \text { ) }\end{array}$ & $\begin{array}{l}4.22^{\star \star \star} \\
(1.79 \text { to } 9.96)\end{array}$ & $\begin{array}{l}5.93^{\star \star \star} \\
(2.93 \text { to } 12.00)\end{array}$ & $\begin{array}{l}13.82^{\star \star \star} \\
(5.91 \text { to } 32.30)\end{array}$ & $\begin{array}{l}12.38^{\star \star \star} \\
\text { (5.79 to } 26.46 \text { ) }\end{array}$ \\
\hline Number of survivors to discharge (\%) & $23(4.4)$ & $32(5.8)$ & $7(4.8)$ & $5(8.9)$ & $7(7.2)$ & $11(15.7)$ & $9(8.4)$ \\
\hline Crude odds ratio $(95 \% \mathrm{CI})$ & $1.00(-)$ & $\begin{array}{l}1.33 \\
(0.77 \text { to } 2.30)\end{array}$ & $\begin{array}{l}1.09 \\
(0.46 \text { to } 2.58)\end{array}$ & $\begin{array}{l}2.12 \\
(0.77 \text { to } 5.80)\end{array}$ & $\begin{array}{l}1.68 \\
(0.70 \text { to } 4.03)\end{array}$ & $\begin{array}{l}4.03^{\star \star \star} \\
(1.87 \text { to } 8.66)\end{array}$ & $\begin{array}{l}1.98 \\
(0.89 \text { to } 4.41)\end{array}$ \\
\hline Adjusted odds ratio $(95 \% \mathrm{CI})$ & $1.00(-)$ & $\begin{array}{l}3.55^{\star \star} \\
\text { (1.62 to } 7.79)\end{array}$ & $\begin{array}{l}1.76 \\
(0.59 \text { to } 5.29)\end{array}$ & $\begin{array}{l}3.24^{\star} \\
(1.03 \text { to } 10.20)\end{array}$ & $\begin{array}{l}2.79 \\
(0.98 \text { to } 7.94)\end{array}$ & $\begin{array}{l}20.88^{\star \star \star} \\
(6.72 \text { to } 64.94)\end{array}$ & $\begin{array}{l}9.11^{\star \star \star} \\
\text { (3.12 to } 26.61 \text { ) }\end{array}$ \\
\hline
\end{tabular}

${ }^{\star} \mathrm{p}<0.05,{ }^{\star \star} \mathrm{p}<0.01,{ }^{\star \star \star} \mathrm{p}<0.001$.

$\mathrm{CI}$, confidence interval; HP, health professional; MP, medical practitioner. 
combination of a paramedic crew and a medical practitioner appeared to make a significant difference to survival chances, but after adjusting for all factors known to influence outcome, the chances of a patient surviving to hospital discharge were significantly better when a paramedic crew was either unassisted or assisted by a medical practitioner or health professional, and when assistance was provided by a medical practitioner to a technician crew.

\section{Discussion}

Survival from out-of-hospital cardiac arrest in Nottingham remains extremely poor despite the introduction of paramedics. Our overall rate of survival to hospital discharge of $6.1 \%$ for all cardiac arrhythmias and $11.7 \%$ for ventricular fibrillation is similar to other ambulance services in the United Kingdom, ${ }^{19}{ }^{10}$ but much less than that of $28.9 \%$ in Seattle, USA. ${ }^{11}$ Paramedic skills of ambulance staff have been shown by Lewis et al to increase the likelihood of successful resuscitation ${ }^{12}$, but from the perspective of accident and emergency department based research, paramedics did not have a major impact on survival, as Guly has reported in Edinburgh. ${ }^{3}$

From our study, resuscitation by a paramedic crew resulted in better rates of survival, to both hospital admission and discharge from hospital, compared with a technician only crew. The provision of defibrillation plus basic life support by technicians appears to be inadequate in improving survival compared with the complementary early provision of advanced cardiac life support by paramedics. Complicated arrests attended by a technician calling for a backup paramedic inevitably delayed the delivery of ACLS. Though more patients were kept alive to reach hospital, most of these $(75.9 \%)$ died shortly after admission, so delayed delivery of ACLS seems ineffective in reducing mortality from out-of-hospital arrest.

The availability of a third person in a resuscitation attempt might be better than the two person method of resuscitation ${ }^{13}$ owing to prompt and effective delivery of ACLS. This is supported by our study, since survival to hospital admission was significantly superior when ambulance crew were assisted by a medical practitioner or other resuscitation trained professional. This might be the result of selection bias, but this is difficult to establish for two reasons. First, the medical practitioner may recommend termination of or persistence with resuscitation efforts, based on knowledge of the patient and the medical background; and second, Nottinghamshire Ambulance Service protocols require ambulance personnel to maintain resuscitation, once initiated, until arrival at hospital or unless otherwise advised by the medical practitioner.

If a member of the Nottingham public sustains a cardiac arrest in the community, how might their chances of survival be increased apart from provision of early ACLS by paramedic ambulance crews? The options are to train community members to provide basic life support until an ambulance crew arrives, to reduce the call to arrival time of ambulances, or to increase the number of medical and other resuscitation trained professionals to provide basic and advanced resuscitation which must include defibrillation.

Community training is being provided in Brighton $^{14}$ and Seattle ${ }^{15}$; in Seattle nearly $60 \%$ of residents aged 12 years and over have had some formal training in cardiopulmonary resuscitation, but this may not be the most effective or cost-effective way of improving survival in Nottingham, for we would need to train about half a million people if we are to provide community resuscitation similar to that in Seattle.

A more rapid response to a call for help, and so a reduction in the time to first defibrillation can lead to a greater proportion of patients surviving a community arrest. ${ }^{1}$ Nottingham ambulances take a median of six minutes to respond to a call for help, which appears by comparison too long (mean of 2.7 minutes in Rochester ${ }^{16}$ and 3.6 minutes in Seattle ${ }^{17}$ ) and may well be difficult to reduce. The introduction of a priority dispatch system may reduce call out times but it may still be necessary to enlarge either the pool of vehicles or the number of paramedics available.

The value of medical practitioners was first reported in 1977 in a review of Nottingham's technician training programme. ${ }^{18}$ Medical assistance may improve survival to hospital discharge, with hospital discharge rates varying between $28 \%$ and 50\%. ${ }^{49-21}$ Encouraging all general practitioners who attend emergency calls to assist ambulance crew is unrealistic for two reasons. First, few practitioners could achieve the response time of a 999 call ambulance crew. Second, many health authorities recommend that patients make a 999 call instead of or before calling for a doctor, but attempts at public education to get patients into hospital earlier by this initiative had limited success. ${ }^{22}$ Even so, general practitioners could be encouraged to undertake training in advanced life support and to carry a defibrillator so that if an arrest occurs when in attendance, prompt defibrillation or provision of basic life support until the arrival of ambulance crew, and his subsequent assistance at the scene, would have an immediate impact and be life saving. This might be especially appropriate for rural practices, where paramedic or technician ambulance crew may have long journey times.

There is no doubt that cardiopulmonary resuscitation in the community can be life saving. Since the introduction of basic, and later of advanced, resuscitation training, many patients have survived the acute event and been discharged from hospital. Now that Nottinghamshire Ambulance Service has almost completed the training and deployment of the recommended number of paramedics, a patient's chances of survival appear to be greatest when ambulance crew have an extra pair of trained hands available to assist them. How such assistance might be provided remains to be seen-certainly anyone trained in even basic resuscitation should maintain their skills as they may make a significant contribution to the management of cardiac arrest in the community. 
1 Cobbe SM, Redmond MJ, Watson JM, et al. Heartstart Scotland-initial experience of a national scheme for out of Scotland-initial experience of a national scheme
hospital defibrillation. BMF 1991;302:1517-20.

2 Eisenberg M, Horwood B. Cummins RO, et al. Cardiac arrest and resuscitation: a tale of 29 cities. Ann Emerg Med 1990;19:179-86

3 Guly UM, Mitchell RG, Cook R, et al. Paramedics and technicians are equally successful at managing cardiac arrest outside hospital. BM7 1995;310:1091-4.

4 Grubb NR, Elton RA, Fox KAA. In-hospital mortality after out-of-hospital cardiac-arrest. Lancet 1995;346:417-21.

5 Gray D, Hampton JR. Twenty years' experience of myocardial infarction: the value of a heart attack register. $\mathrm{Br} \mathcal{F} \mathrm{Clin}$ Pract 1993;47:292-5.

6 Cummins RO, Chamberlain DA, Abramson NS, et al. Recommended guidelines for uniform reporting of data from out-of-hospital cardiac arrest: the Utstein style. Task Force of the American Heart Association, the European Resuscitation Council, the Heart and Stroke Foundation of Canada, and the Australian Resuscitation Council [see Canada, and the Australian Resuscitation

7 Townsend P. Simpson D, Tibbs N. Inequalities in health in Townsend P. Simpson D, Tibbs N. Inequalities in health in the city of Bristol: a preliminary review

$8 S$-plus guide to statistical and mathematical analysis, version 3.3. Seattle: StatSci, 1993.

9 Weston CF, Stephens MR. An audit of cardiac arrest management by extended trained ambulance crew. Resuscitation 1992;23:207-16.

10 Wright D, Bannister J, Ryder M, et al. Comparison of two methods of transporting paramedics to cardiac arrests outside hospital. Resuscitation 1992;23:193-7.

11 Cobb LA, Weaver WD, Fahrenbruch CE, et al. Communitybased interventions for sudden cardiac death. Impact, limitations, and changes. Circulation 1992;85(suppl I):I-98102 .
12 Lewis S, Holmberg S, Quinn E, et al. Out-of-hospital resuscitation in East Sussex: 1981 to 1989. Br Heart $\mathcal{F} 1993 ; 70$ : 568-73.

13 Hackman BB, Kellermann AL, Everitt P, et al. Threerescuer CPR: the method of choice for firefighter CPR? Ann Emerg Med 1995;26:25-30.

14 Vincent R, Martin B, Williams G, et al. A community training scheme in cardiopulmonary resuscitation. BMF 1984; 288:617-20.

15 Mandel LP, Cobb LA. CPR training in the community. Ann Emerg Med 1985;14:669-71.

16 White RD, Vukov LF, Bugliosi TF. Early defibrillation by police: initial experience with measurement of critical time intervals and patient outcome. Ann Emerg Med 1994;23: 1009-13.

17 Weaver WD, Hill D, Fahrenbruch CE, et al. Use of the automatic external defibrillator in the management of out-ofhospital cardiac arrest. N Engl f Med 1988;319:661-6.

18 Hampton JR, Dowling M, Nicholas C. Comparison of results from a cardiac ambulance manned by medical or non-medical personnel. Lancet 1977;i:526-9.

19 Pai GR, Haites NE, Rawles JM. One thousand heart attacks in Grampian: the place of cardiopulmonary resuscitation in general practice. BMF 1987;294:352-4.

20 Kimman GP, Ivens EM, Hartman JA, et al. Long-term survival after successful out-of-hospital resuscitation. Resuscitation 1994;28:227-32.

21 GREAT Group. Feasibility, safety, and efficacy of domiciliary thrombolysis by general practitioners: Grampian region early anistreplase trial. BMf 1992;305:548-53

22 Blohm M, Hartford M, Karlson B, et al. An evaluation of the results of media and educational campaigns designed to shorten the time taken by patients with acute myocardial infarction to decide to go to hospital. Heart 1996;76:430-4. 